
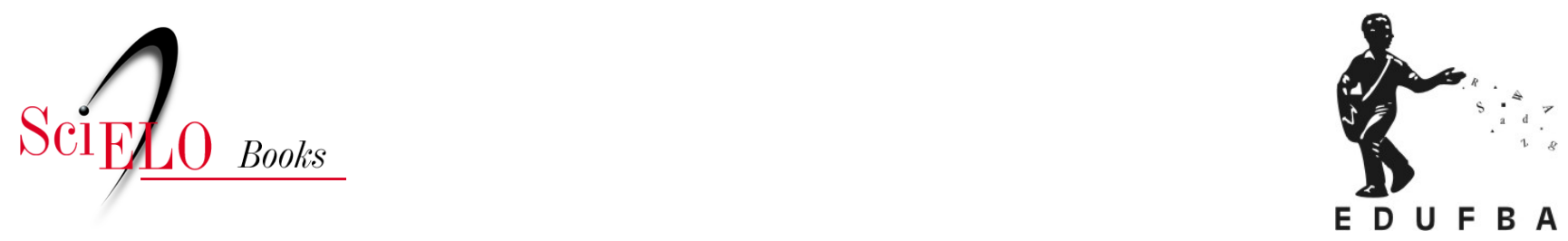

\title{
1. Primeiras remadas do percurso
}

\author{
Nerivaldo Alves Araújo
}

ARAÚJO, N.A. Primeiras remadas do percurso. In: Poética oral do samba de roda das margens do Velho Chico [online]. Salvador: EDUFBA, 2016, pp. 17-40. ISBN: 978-85-232-2031-0.

https://doi.org/10.7476/9788523220310.0002.

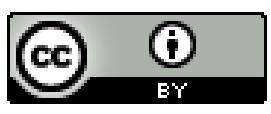

All the contents of this work, except where otherwise noted, is licensed under a Creative Commons Attribution 4.0 International license.

Todo o conteúdo deste trabalho, exceto quando houver ressalva, é publicado sob a licença Creative Commons Atribição 4.0. 



\section{Primeiras remadas do percurso}

Para dar início a esta viagem poética por entre as águas da cultura popular das margens do Velho Chico, nada mais oportuno do que se apresentar, logo nos primeiros momentos de escrita, uma das cantigas do samba de roda que integra a poética oral ribeirinha na região de Xique-Xique:

No Rio São Francisco

Tem duas coisinhas belas

Cabeça de curimatá

Beijinho de moça donzela

Não! No Rio São Francisco, não tem somente duas coisinhas belas, como retrata essa cantiga do grupo de samba de roda, o qual se constitui em objeto deste estudo. Para além da “cabeça de curimatá” e do “beijinho de moça donzela”, tem toda uma riqueza cultural, dentre a qual destaca-se uma poética oral que retrata, nos seus versos, um conjunto plural de gostos, símbolos, representações, fazeres, ideologias, crenças e opiniões.

Assim, ao trilhar esse percurso, remando pelas águas do Velho Chico, a cultura popular ribeirinha da região de Xique-Xique envolve, fascina e, por meio das suas mais diversas manifestações, permite que se adentre nas águas de suas narrativas, suas poesias, suas danças. Navegar por essa cultura das margens do Velho Chico proporciona ao navegante o conhecimento dos encantos da poética oral ribeirinha, cujo samba de roda, considerado uma das suas manifestações mais expressivas, permite compreender a construção das identidades dos povos desse lugar.

Para que se possa compreender e conhecer a tecedura dessas identidades, faz-se necessário, previamente, considerar que esse é um processo, o qual se assemelha à própria trama das redes de pesca dos pescadores. Para tanto, vale apreciar mais uma das cantigas ribeirinhas: 
Ô linha, linhava ô

Eu também sei linhar, ô linhava

Ô linha, linhava ô

Eu também sei linhar, ô linhava

Assim como as redes de pesca, cujas tramas de suas malhas são construídas fio a fio, especialmente pelas mulheres tecedeiras, enquanto cantam as suas cantigas e em meio a uma roda de samba e outra, as identidades dos povos da região também se consolidam sob a forma de alinhavo, ${ }^{1}$ dentro de uma trama que envolve uma série de elementos e influências, a qual será discutida nesta obra.

A tecedura das redes leva em consideração diversas circunstâncias, tais como o tipo de peixes a que se destinam fisgar, o modo e a época da pesca, a força das águas, dentre outras. No tecer das identidades, há influência de diversos fatores e objetivos que acabam agindo num processo perene de construção.

Aqui, retrata-se, em especial, o samba de roda do grupo "É na pisada ê", o qual se constitui como objeto deste estudo, sendo utilizado como referência e exemplos, pois as suas cantigas ajudam a compor o cenário da poética oral ribeirinha. Assim sendo, faz-se necessário entender, nesse contexto, a poética oral como toda produção literária manifestada oralmente, utilizando-se de versos, rimas, métricas e outros elementos da poesia, realizada, como afirma Zumthor (1993), em presença, com a força do corpo e de todos os procedimentos básicos e vitais que o governam, isto é, com as suas práticas performáticas. A obra poética é, ainda de acordo com Zumthor (2005, p. 144), "o fruto da conjunção de um dado textual e de uma ação sociocorporal, um e outro formalizados de acordo com uma estética”.

Nesse sentido, o samba de roda desses povos ribeirinhos, por meio da arte de criar poesia ou compor os versos de suas cantigas, em alguns aspectos como a estrutura e a forma, pode ser visto como parte integrante da poética oral das margens do Velho Chico, sendo que tais elementos poéticos, de certa forma, acabam aproximando-o do rol das práticas literárias de cunho oral.

1 Alinhavo é uma espécie de cosimento provisório. Alinhavar, de acordo com o Michaelis Moderno Dicionário da Língua Portuguesa, significa uma forma de costurar com pontos largos, de modo temporário, como se traçando os lineamentos gerais, um certo tipo de esboço, de preparo (WEISZFLOG, 2009). No texto, tal verbo sofre uma alteração para "linhavar", devido ao modo em que aparece pronunciado nas cantigas (linhava), originando, ainda, outra forma verbal encontrada aqui: "linhavando". 
De acordo com depoimentos dos próprios integrantes, como a sra. Anita, de 78 anos, uma das suas líderes, o grupo existe desde o início do século XX. A comunidade de sambadeiras e sambadores ${ }^{2}$ está localizada no antigo bairro de Paramelos, nas margens do Rio São Francisco, na cidade de Xique-Xique, estado da Bahia. Adiante, será apresentado um estudo mais aprofundado sobre a história, as características e demais informações a respeito do grupo.

Torna-se necessário ressaltar, de início, que a palavra "margem" assume neste texto, não somente o sentido de beira do rio, mas também, de um lugar de desmerecimento, de discriminação sociocultural, estabelecido a partir de um centro canônico. Isso ocorre devido ao fato de se realizar, nas margens do rio, o estudo de uma poética oral ribeirinha, muitas vezes marginalizada, desmerecida por uma elite cultural que se ampara em valores eurocêntricos, patriarcais, grafocêntricos e, na maioria das vezes, cristãos.

Faz-se, portanto, uma relação com o fato de trazer, para o centro das discussões, uma poesia que se localiza geograficamente nas margens do Rio São Francisco, em comunidades ribeirinhas, e também por ser um produto cultural de comunidades de situação econômica desfavorável, com uma cultura que foge aos padrões conceituais e estéticos da dos dominantes.

Nesse sentido, a palavra "margem" surge, muitas vezes, como lugar a que estão destinadas as manifestações da cultura popular, cujas práticas, valores e características são de caráter específico, diferenciando-se da cultura hegemônica e eurocêntrica, considerada como verdadeiramente tradicional por uma elite conservadora. Tais práticas fazem parte, conforme Ferreira (2010), de uma espécie de cultura das bordas, as quais sofrem um processo de exclusão do centro, ficando em uma faixa de transição entre as culturas tradicionais - como as manifestações folclóricas - e a cultura dos que detêm maior atualização, prestígio e poder. Por isso, procura-se acrescentar a qualificação "oral” ou "popular" à palavra "tradição", quando se pretende fazer referência à poética ribeirinha, para que não se confunda com tradição hegemônica.

2 Aqueles moradores das margens do Velho Chico, mulheres, homens, jovens e crianças, integrantes dos grupos de samba de roda que participam cantando, sambando, tocando instrumentos ou compondo as letras e melodias, aparecem neste texto, na maioria das vezes, assim denominados por gênero feminino e masculino. Por motivos estruturais, em alguns momentos, utiliza-se apenas a palavra "sambador", de forma generalizada. 
A expressão "poesia/poética das margens do Velho Chico" aparece também por ser tal manifestação poética, constituída de marcas culturais dos povos marginalizados e subalternizados como os negros e os índios, ainda por se distanciar dos moldes da poesia clássica, escrita.

Torna-se pertinente destacar também, a fim de não gerar expectativas não contempladas pelos objetivos aqui trazidos, que não se teve a pretensão de se estender a um estudo aprofundado do samba sinônimo de gênero musical, composto de letra, melodia, ritmos, notas, acordes, harmonia e demais aspectos relacionados a esse âmbito. Desse viés, serão trazidas apenas algumas informações menos específicas ou técnicas que sejam necessárias ao entendimento das discussões sobre o tema em foco e de domínio do pesquisador. Por parte deste, seria necessária uma formação específica na área de música ou, pelo menos, um conhecimento bem mais aprofundado do assunto, para que tais questões fossem discutidas.

Também não se pretende fazer um estudo antropológico ou sociológico do grupo de samba, mas apenas utilizar-se de algumas informações e conceitos dessas áreas para fomentar as percepções e análises trazidas. Conforme já foi dito, o samba será prioritariamente tomado como objeto deste estudo, enquanto um gênero da poética oral ribeirinha, com suas cantigas e práticas performáticas como a dança, o gingado e demais representações. A tecedura das identidades do grupo será apresentada, essencialmente, a partir desse campo de abordagem.

Nota-se que a cultura desses povos ribeirinhos vem se destacando e se mantém cada vez mais forte em suas comunidades, embora se saiba que culturas como essas têm sofrido, no decorrer dos tempos, um processo de subalternização por uma corrente eurocêntrica, implantada desde a colonização europeia. Essa corrente ideológica, na maioria das vezes, desqualifica as demais formas que fogem aos padrões da cultura hegemônica, pois, como se tem conhecimento, segundo Ortiz (2003), há uma tendência à inserção da manifestação popular em um espaço de subordinação que, arbitrariamente, é imposto a partir do alto.

Não há, entre a cultura popular e a cultura hegemônica, uma relação de alienação, como até pode parecer, mas uma relação de forças, em que o grupo cultural, detentor do poder econômico, determina, classifica e exclui. Tal circunstância vem contribuindo para que esses povos de culturas marginalizadas passem a adotar práticas capazes de promover a sua sobrevivência diante de situação desfavorável, as quais podem ser consideradas como práticas de aquilombamento. 
A expressão "aquilombamento" provém de "aquilombar", que, segundo os dicionários, dentre eles o Michaelis Moderno Dicionário da Língua Portuguesa (WEISZFLOG, 2009), significa "reunir-se em quilombo", "dar aspecto de quilombo". Dessa forma, o aquilombamento passa a ser visto como uma prática de resistência, de luta, uma forma de reunião para resistir, lutar contra as situações desfavoráveis e subalternizantes, às quais os negros e suas práticas são expostos na sociedade, ainda nos dias de hoje.

De acordo com Munanga (1996), quilombo se constitui em campos de iniciação à resistência, considerados como espaços de acolhimento a todos os oprimidos da sociedade, constituindo-se num modelo prévio de democracia plurirracial que o Brasil ainda permanece em busca. Para tanto, são válidas as considerações de Munanga (1996, p. 58, 63) sobre o conceito de quilombo:

O quilombo é, seguramente, uma palavra originária dos povos de língua bantu (kilombo, aportuguesado: quilombo). Sua presença e seu significado no Brasil têm a ver com alguns ramos desses povos bantu, cujos membros foram trazidos e escravizados nesta terra [...] tem a conotação de uma associação de homens, aberta a todos sem distinção de filiação a qualquer linhagem, na qual os membros eram submetidos a dramáticos rituais de iniciação que os retiravam do âmbito protetor de suas linhagens e os integravam como co-guerreiros num regimento de super-homens invulneráveis às armas de inimigos. $\mathrm{O}$ quilombo amadurecido é uma instituição transcultural que recebeu contribuições de diversas culturas: lunda, imbangala, mbundu, kongo, wovimbundo etc. [...] São campos de iniciação à resistência, campos esses abertos a todos os oprimidos da sociedade (negros, índios e brancos), prefigurando um modelo de democracia plurirracial que o Brasil ainda está a buscar.

Assim sendo, aquilombar-se consubstancia-se em toda forma de resistir à opressão das minorias, não somente como espaço físico de resistência, mas quaisquer outras, como música, dança, literatura e outras manifestações artístico-culturais. É por isso que se pode considerar o samba de roda como uma forma de aquilombamento, porque, neste espaço de memória, mantêm-se vivas as tradições de uma comunidade, resistindo, durante a sua história, a toda forma de subalternização e desmerecimento. 
Vale ressaltar que os povos dessa comunidade carregam, em si, marcas da origem africana, não apenas no aspecto fenotípico, mas também nas questões culturais e religiosas. Logo de princípio, já se torna possível deduzir que a sua cultura e a sua religião trazem a marca da pluralidade e da diversidade, uma vez que se constroem a partir de uma mistura entre as principais etnias formadoras da cultura brasileira: indígena, ${ }^{3}$ portuguesa e africana.

Essas etnias formadoras, em sua unidade, são também construídas dentro de uma perspectiva plural, como no caso da africana, a qual se consolidou no Brasil, em uma junção de vários povos vindos do continente africano. De modo semelhante, processa-se também com a indígena e a portuguesa, pois, na região, havia a presença de várias tribos de índios com suas práticas culturais, as quais se diferenciavam em alguns aspectos das outras matrizes. Quanto à portuguesa, esta aparece também influenciada por outras culturas, desde o processo de formação da nação lusitana, a partir de povos latinos, fenícios, muçulmanos e outros. E os estudos aqui realizados, com os elementos e considerações apresentadas poderão claramente comprovar essas ideias de pluralidade, de diversidade das identidades e das culturas, tão visíveis dentro da poética oral ribeirinha.

A colonização da região do locus da pesquisa, da qual se originou esta obra, ocorreu sob o comando da Casa da Torre, e sofreu - segundo a sua história disponível no site do Instituto Brasileiro de Geografia e Estatística (IBGE), crônicas, blogs e páginas oficiais do governo - influências de uma grande diversidade populacional composta por portugueses, africanos escravizados, brasileiros, filhos de portugueses, mestiços de branco e índio, índios puros, também por holandeses e espanhóis. Tal processo de diversificação cultural continuou ocorrendo na história da região até o dia de hoje, devido à chegada de povos de outras nacionalidades e culturas.

A memória cultural dos povos ribeirinhos tem, nessa confluência étnico-racial, sua força e riqueza, embora a visão etnocêntrica da cultura hegemônica considere isso como impureza e falta de originalidade, motivo utilizado para relegá-la a um patamar inferior.

Segundo Neves (2009), a presença da população negra e de sua cultura em todo o São Francisco é bastante remota e, desde o início da colonização de suas

3 Em outros momentos no texto, aparece a palavra "ameríndia" com o mesmo sentido de "indígena", pois ambas se referem aos povos que habitavam as terras brasileiras antes da chegada dos colonizadores portugueses. Assim, ambas as palavras se alternam no texto, mas adotando o mesmo significado. 
margens, os negros ocupavam uma posição de subalternidade dentro da estrutura social, mesmo depois da abolição da escravidão oficial, uma vez que continuaram em troca de escassa remuneração, a se empregar na lavoura e em pequenos ofícios urbanos.

Quanto aos indígenas, Neves (2009) destaca que, desde o século XVII, já se processavam os primeiros contatos do homem branco com os índios cariris que habitavam as suas margens. Assim, a cultura ribeirinha do Velho Chico é bastante marcada também pela influência dessas vértices indígenas e africanas, que, por muitos anos, vêm sendo submetidas a um processo de subalternização.

A pluralidade cultural e as marcas da afrodescendência causam ainda mais desprestígio dessas manifestações da tradição popular, diante de uma elite socioeconômica e cultural, de mentes colonizadas e visão afropessimista, reafirmada pelo discurso do "branqueamento". ${ }^{4}$ (FANON, 2008) Tal fato é estimulado por parcelas da sociedade, através da mídia e da literatura, que, mesmo diante de políticas governamentais de igualdade e outras ações sociais desse porte, ainda costumam, em muitos casos, atrelar a imagem do negro e da sua cultura a estereótipos negativos, reforçando o preconceito criado no Brasil desde a época da colonização.

Essa situação tem revelado, em inúmeras circunstâncias, a consolidação de uma imagem negativa sobre o negro, o que lhe conduz, muitas vezes, à negação de sua própria identidade negra. ${ }^{5}$ Isso, segundo Fanon (2008), resulta da opressão do colonizador sobre o colonizado, do branco sobre o negro, o qual, muitas vezes, chega a vestir a máscara branca para poder existir dentro desse contexto. É o que o próprio autor aponta como um processo de colonização mental, pelo qual todos nós passamos, sendo brancos ou negros, consolidando-se numa forma de escravidão mental do sujeito negro face às pressões sociais.

Dessa maneira, sabe-se que, conforme destacam Serrano e Waldman (2010, p. 12), tal realidade, em muitos casos, se aplica

4 Expressão utilizada por Frantz Fanon (2008) quando se refere ao desmerecimento de todos os aspectos referentes ao negro e à sua cultura em relação ao branco. Ver a obra do referido autor: Pele negra, máscaras brancas.

5 "Identidade negra", neste estudo, assume a mesma relação semântica com "identidade afrodescendente", sendo que, sobre a expressão "afrodescendente", traz-se, mais adiante, uma explicação acerca da sua significação. 
Aos segmentos da população brasileira de origem africana que, desde os primórdios da colonização, com o concurso da discriminação racial, tiveram as suas práticas ancestrais abafadas, marginalizadas e/ou deturpadas, comprometendo, assim, a sua inserção plena no processo social brasileiro mais amplo.

Ainda segundo Serrano e Waldman (2010), a estereotipia negativa sobre a África e seus povos é chamada de afropessimismo, considerado como estratégia que opera com generalizações, preconceitos e falsas concepções, com o intuito de confirmar a submissão do continente, alegando que este seria incapaz de gerir seu próprio destino. Esse afropessimismo apresenta uma coleção de imagens negativas sobre a África, como fruto de um vetor ideológico de uma Europa que ambicionava dominá-la, arrogando-se o papel de dominante.

Desse modo, mesmo não sendo composta de traços exclusivamente afrodescendentes, a cultura popular ribeirinha xiquexiquense tende a ser marginalizada. Todavia, essa cultura não se deixa abater diante de um contexto desfavorável.

Descrito pelo Dossiê do samba de roda do Recôncavo baiano (2006) como uma manifestação musical, coreográfica, poética e festiva que se encontra presente em todo o estado da Bahia, o samba de roda se estabelece como uma prática cultural, uma forma de resistência que se apoia na diversidade, pois, de acordo com o respectivo Dossiê,

O samba de roda, desde antigos relatos, traz como suporte determinante tradições culturais transmitidas por africanos escravizados no Estado da Bahia. Essas tradições se mesclaram de maneira singular a traços culturais trazidos pelos Portugueses [...] e à própria língua portuguesa e elementos de suas formas poéticas. Tal mescla, assim como outras mais recentes, não exclui o fato de que o samba de roda foi e é essencialmente uma forma de expressão de brasileiros afrodescendentes, que se reconhecem como tais. (SAMBA..., 2006, p. 24)

Dessa maneira, a poética oral do samba de roda ribeirinho passa a representar a cultura popular, a evidenciar suas marcas identitárias, pois se constitui de letra (texto oral poético), que ainda se completa com outros aspectos capazes de enriquecer toda a textualidade, tais como a poesia, o ritmo, o movimento, a representação, a performance, o riso, a alegria e outros. 
O samba de roda, em meio aos diversos gêneros da cultura popular das margens do Velho Chico, vem adquirindo uma notoriedade maior dentre as práticas culturais ribeirinhas. Através de sua poética oral, os registros de conhecimento de mundo, os valores, as crenças, enfim, toda a história de vida, toda a cultura desse povo perpetua-se entre as diversas gerações, sobrevivendo dentro de uma memória coletiva, fazendo parte, segundo Bhabha (2003), de um processo social de representações, de reprodução e de reelaboração simbólica.

A comunidade poética da qual fazem parte as sambadeiras e sambadores ribeirinhos, autores de suas histórias, cantigas, danças, enfim, de toda uma poética particular, constitui-se num espaço de resistência e de preservação da memória cultural, em especial, a memória afrodescendente, pois traz, em si, as marcas de uma cultura híbrida, rica e diversificada.

García Canclini (2006) teoriza a hibridização quando a considera como processos socioculturais, nos quais, estruturas ou práticas discretas, que existiam de forma separada, combinam-se para gerar novas estruturas, novos objetos e novas práticas.

Já não é mais possível defender um conceito de cultura centrado na homogeneidade, numa visão tradicional, a qual desconsidera as variedades de influências, pois

\footnotetext{
Os próprios conceitos de culturas nacionais homogêneas, a transmissão consensual ou contígua de tradições históricas, ou comunidades étnicas "orgânicas" - enquanto base de comparativismo cultural -, estão em profundo processo de redefiniç̧ão. (BHABHA, 2003, p. 24, grifo do autor)
}

Nesse sentido, as manifestações culturais de povos frequentemente marginalizados pela cultura dos grupos dominantes de visão eurocêntrica estão assumindo um papel considerável ante o novo repensar da cultura nacional.

Torna-se pertinente, então, com o intuito de melhor informar o leitor, trazer algumas considerações acerca da significação para comunidade poética, a qual pretende abraçar, neste espaço, todos os gêneros da poética oral ribeirinha, uma vez que a poesia do samba de roda também traz, em si, a história de seu povo, a representação em seus versos, aliados às práticas performáticas de suas tradições, costumes e atividades cotidianas. Quando sambam, ao ritmo de suas 
cantigas, acabam, de certo modo, pintando um retrato de sua história, de sua cultura. Dessa forma, os seus moradores constroem o sentido de pertencimento e se reconhecem como próprios personagens e atores dessas representações poético-culturais.

Sendo assim, o sentido utilizado para comunidade poética, é de um espaço de conhecimento mútuo de uma cultura e de sua poética oral, no qual um povo estabelece uma relação de pertencimento por comungar das mesmas práticas desenvolvidas, tendo o hábito de compartilhá-las, recriá-las e performatizá-las entre o seu público, numa unidade interdependente, indissociável e dinâmica. No caso da poética oral deste samba de roda em estudo, as sambadeiras e sambadores e demais participantes das rodas de samba comungam do conhecimento das cantigas, ritmos, danças e demais atividades performáticas.

Tal ideia advém das palavras de Nogueira (1999), ao considerar uma comunidade como um grupo de pessoas que partilham um espaço territorial definido, ligadas por um fundo cultural comum e orientadas por relações de estreita convivência e intimidade.

Dessa maneira, para que possam se sentir pertencentes ao grupo, os integrantes desta comunidade poética necessitam, então, conhecer a história do grupo de samba, seus objetivos e justificativas para a sua existência e valor. Todo esse conhecimento compartilhado contribuirá para que o indivíduo possa compreender-se como uma parte dessa comunidade que comunga saberes, histórias, costumes, poesias e tradições.

Vale ressaltar que, para a elaboração do conceito de comunidade poética, utilizou-se, ainda, a ideia de comunidade narrativa trazida por Lima (1985), que considera como tal o conhecimento mútuo de narrativas e o hábito de compartilhá-las, recriá-las e performatizá-las entre narradores e o seu público, numa unidade interdependente, indissociável e dinâmica. Isso foi possível porque, assim como a poética oral, a narrativa oral também é uma espécie de gênero que compõe a cultura popular. Assim, procurou-se criar um espaço específico para acolher a poética oral do samba de roda com as suas danças performáticas e cantigas, elementos que acabam tecendo também a história, representando os costumes, a labuta, a tradição ribeirinha.

Assim, pode-se inferir que a construção da identidade cultural desses povos ribeirinhos, em parte, sustenta-se em sua poética oral, sendo o seu estudo, um dos caminhos para o entendimento da cultura popular e o consequente respeito 
pela mesma, contribuindo para que venha a se sobressair das margens e promovendo a consolidação de uma cultura tida como nacional, cujos pilares se constroem no veio popular.

Sabe-se da importância da cultura popular na construção da identidade nacional. Toda a riqueza cultural que habita nessas margens ribeirinhas não pode ser deixada para trás, à mercê dos ventos, correndo o risco de ser tragada pelas águas do etnocentrismo. Faz-se necessário conhecê-la melhor, para valorizá-la como elemento principal de preservação e de divulgação da memória local. Para tanto, empregam-se registros escritos, gravações de áudio e de vídeo, estudos mais detalhados, a fim de que tal cultura popular possa ser disponibilizada para um maior número de leitores e estudiosos da temática, compartilhando, assim, conhecimentos sobre seus aspectos peculiares, detalhamentos da sua poética oral e do seu samba de roda.

Face à problemática até aqui delineada, busca-se preencher as lacunas para as questões relacionadas à tecedura das identidades culturais ribeirinhas xiquexiquenses e à função do samba de roda "É na pisada ê" nesse processo, ressaltando as suas marcas culturais, presentes em suas cantigas, ritmos e danças performáticas. Na busca das respostas para um entendimento maior do problema, é imprescindível demonstrar como a cultura e as identidades destes povos ribeirinhos vêm sendo representadas nas letras, na performance e na musicalidade do seu samba, quais as principais marcas e valores culturais presentes e em que aspectos a cultura afrodescendente aparece destacada dentro desse gênero da poética oral.

São muitos os elementos considerados relevantes na realidade dos povos dessa região, a exemplo da história da colonização. O próprio Rio São Francisco serviu como via de espraiamento da influência da cultura afrodescendente e apontou outros determinantes, os quais interferiram e ainda interferem nos processos de construção identitária dessas comunidades ribeirinhas que se apresentam regidas pela fluência das águas do rio, a erosão das suas margens e o assoreamento do seu leito, confirmando toda uma espécie de instabilidade do lugar, do seu povo, das suas memórias e das suas identidades.

Desse modo, torna-se mister uma investigação criteriosa da tecedura poética desses povos, em especial, da poesia oral de seu samba de roda, o qual se encontra presente em sua memória coletiva, considerando todo o simbolismo de uma ancestralidade que tem resistido ao preconceito étnico-racial e se impõe 
enquanto memória e história na formação das identidades culturais do lugar, para além dos estereótipos. Ferreira (2004, p. 51-52) aponta que:

O preconceito racial, no Brasil, surgiu a partir da interação entre dois grupos - uma classe política e economicamente dominante que assumiu uma concepção de mundo considerada superior e estigmatizou o outro grupo, neste caso, o dos não brancos, caracterizando-o como de qualidade inferior, crença que passa a ter a função de justificar a dominação sobre ele.

Entende-se que esta obra se torna importante e necessária por permitir adentrar-se em uma cultura peculiar, com uma poética oral, rica e plural, de espaço misterioso e encantador como é o Velho Chico, de personagens guerreiros e resistentes, mas, muitas vezes, fragilizados pela eminência da discriminação cultural. Também, por trazer à pauta um embate cultural existente em nossa sociedade, proporcionando reflexões mais aprofundadas para os problemas relacionados à temática, dentre eles, a possível construção de uma identidade nacional infiel à pluralidade de culturas que a compõe, que não respeite toda uma diversidade de povos e suas práticas.

As reflexões apresentadas pretendem, ainda, contribuir para a inversão de uma tendência em valorizar a cultura do colonizador europeu e desmerecer as culturas populares, que se constroem na diversidade, para que ocorra, então, o reconhecimento institucional dessas identidades culturais locais, a fim de que comunidades como estas possam usufruir da atenção estatal necessária. Essa abordagem temática proporcionará o avivamento de um dos mais expressivos gêneros da poética oral ribeirinha: o samba de roda.

Dessa maneira, almeja-se contribuir para o reconhecimento de que a "porta de entrada" rumo ao fortalecimento da cultura dos povos ribeirinhos possa ser a integração do samba de roda e sua diversidade cultural das "margens" do Rio São Francisco ao "centro" da cultura nacional, porém sem perder a sua excentricidade, suas características peculiares. Através da cadência-correnteza do samba ribeirinho, com suas marcas e singularidades, podem-se notar os perfis identitários dos seus povos e, assim, fazer que estes se movam e se percebam fora da "marginalidade" do Velho Chico, navegando rumo a um centro, a uma valorização, trazendo à tona a sua vida, o seu mundo, a sua história, a sua cultura. 
Faz-se necessário destacar que o registro do samba de roda ribeirinho, por meio das gravações de áudio e vídeo, bem como da transcrição de suas letras, antes de significar uma forma de preservação, são uma forma de divulgação dessa manifestação cultural para além das “margens” do Rio São Francisco. Outros estudos desse tipo poderão ser publicados e disponibilizados em bibliotecas, universidades, livrarias, sites e blogs na internet, passando a servir de ponto de partida para outras pesquisas, registros e publicações, ainda como estímulo para o trabalho com essas culturas em salas de aula. Podem também ser revertidos em material didático para as escolas da própria região e servir de motivação a prefeituras e instituições educacionais ou culturais para um trabalho de valorização, divulgação e ressignificação da cultura popular local.

Convém ressaltar que essa obra não discute exclusivamente sobre a presença da afrodescendência na identidade dos povos ribeirinhos. Dessa forma, não se tratará somente de questões da cultura de origem africana, trazendo e esgotando todas as discussões e conhecimentos sobre a temática. A comunidade ribeirinha, representada pelas sambadeiras e sambadores do grupo "É na pisada ê", compõe um espaço da cultura popular, que se apoia na diversidade e na liquidez, o que contribui para uma reflexão que possa contemplar as marcas da pluralidade cultural.

É importante acrescentar que o termo "afrodescendência” ou "afrodescendente" é empregado aqui para se referir a determinado segmento da cultura brasileira, o qual apresenta marcas da cultura africana, trazidas para o Brasil pelos negros escravizados durante a colonização e que, ao chegar aqui, devido às circunstâncias locais impostas pelo colonizador - a exemplo da união e da convivência entre povos de diversas tribos e culturas africanas -, assumiram características diferenciadas, mas sem perder a sua ligação com as demais etnias responsáveis pela formação da nossa cultura.

Em conformidade com Fonseca (2006), a afrodescendência relaciona-se, neste texto, às questões que dizem respeito à presença de tradições africanas disseminadas na cultura brasileira. Para que se possa compreender melhor essa relação, faz-se necessário perceber que:

[...] as expressões 'afro-brasileiro' e 'afro-descendente' circulam com maior desenvoltura, afirmando-se, sobretudo, quando são discutidas questões relacionadas com determinados segmentos da cultura 
brasileira. O uso dessas expressões não esgota as complexas questões que circulam em torno de seus significados, mas pode revelar, certamente, um modo de se considerar a pluralidade como um traço da cultura brasileira. (FONSECA, 2006, p. 38)

Sendo assim, não se pretende criar um tensionamento, uma discussão em torno de qual o termo mais adequado para ser utilizado aqui, mas apenas deixar clara a sua abrangência e significação, a fim de não criar conflitos teóricos.

As considerações trazidas amparam-se, inicialmente, na vertente dos Estudos Culturais vistos a partir de uma visão interdisciplinar, em que diversos estudos se consolidam, baseando-se na cultura como uma espécie de conceito central. A cultura é vista, aqui, como um texto amplo e contínuo, composto de camadas que se sobrepõem a todo instante, trocando informações e construindo novos textos. É algo dinâmico, que se estabelece de forma política e consciente. Já a ideia de cultura popular deve, segundo Ortiz (2003), ultrapassar a barreira da assimilação com a tradição e ir mais além, confundindo-se também com ideia de conscientização, de ação política, de crenças, valores e posicionamentos que representem o povo. Isso porque:

‘Cultura Popular’ não é, pois, uma concepção de mundo das classes subalternas [...] nem sequer os produtos artísticos elaborados pelas camadas populares, mas um projeto político que utiliza a cultura como elemento de sua realização. (ORTIZ, 2003, p. 72)

Baseando-se nessa concepção de cultura, são trazidas reflexões sobre o samba de roda como um dos principais modos de expressão da cultura popular brasileira, que representa as identidades do seu povo. Para isso, tornou-se fundamental conhecer um pouco sobre a história, as características e a composição do samba de roda da Bahia e da região do São Francisco. Conhecer um pouco da história e da colonização da região proporcionou a compreensão dos aspectos culturais do povo das margens do Velho Chico.

Buscou-se ancorar a pesquisa numa abordagem das teorias voltadas à temática da construção da identidade cultural, da consolidação da memória cultural e do hibridismo das culturas. Estudos sobre performance e corporeidade se fizeram pertinentes, a fim de que se pudesse compreender a importância desses 
elementos na composição da cultura e das identidades dos ribeirinhos, como também o conhecimento de elementos simbólicos que fazem parte do seu imaginário e da sua tradição.

Aportou-se teoricamente em temas voltados para a cultura afrodescendente, sua história, seus valores, suas marcas e influência na construção da cultura popular brasileira. Os aspectos temáticos relacionados à construção da identidade afrodescendente são apresentados, sem deixar de enfatizar as peculiaridades dessa cultura, muitas vezes, silenciada e ressignificada por imposição de uma elite branca, de visão eurocêntrica, patriarcal, cristã e grafocêntrica.

Assim sendo, para dar conta da problematização da tríade "cultura popular, samba de roda e identidades”, as elaborações dos Estudos Culturais apresentamse como contribuição para elucidar questões relacionadas à memória e à história das culturas, os encontros, os choques e os hibridismos entre elas, assim como possibilitam investigar as representações culturais e as suas implicações subjacentes.

\section{Etapas da viagem}

Para seguir em viagem pela cultura popular das margens do Velho Chico, ao ritmo das suas águas, buscando-se conhecer a tecedura das identidades culturais dos povos ribeirinhos, representadas por meio da poética oral do seu samba de roda, principal objeto deste estudo, foram adotados alguns procedimentos metodológicos específicos e qualificados para que se pudesse chegar ao conhecimento pretendido.

Com o objetivo de melhor compreender as nuances dessas identidades ribeirinhas, o caminho metodológico escolhido buscou seguir os princípios e as determinações da pesquisa qualitativa de cunho etnográfico, tendo como aporte metodológico as trilhas dos estudos culturais e a visão de totalidades - no que se referem às artes, crenças, instituições, práticas sociais, culturas, identidades, aos valores, dentre outros fatores que estão inseridos em todo um universo discursivo -, contudo, sem se afastar do viés literário com seu estilo e poética, a vertente principal desta obra.

O procedimento adotado na pesquisa procurou abarcar não só uma investigação stricto sensu no eixo samba de roda e identidades, mas observar concei- 
tos e preceitos provenientes de outras áreas que possam responder aos nossos questionamentos. Para tanto, tornou-se fundamental uma incursão pelos aportes bibliográficos e documentais sobre a temática em discussão, bem como uma pesquisa de campo, com o grupo de samba "É na pisada ê".

Os caminhos trilhados pelo pesquisador são aqueles que permitem contemplar, baseado em concepções contemporâneas sobre o processo de conhecimento, o real como um "[...] fenômeno cultural, histórico e dinâmico, cuja complexidade não deve ser rompida, como um tecido que não pode ser esgarçado sem o risco de se perder sua identidade e, portanto, sem a possibilidade de ser conhecido”. (FERREIRA, 2004, p. 27)

Nesta pesquisa, há uma relação estabelecida no processo de construção de sentidos, em que o pesquisador e os demais participantes estão envolvidos. Contudo, faz-se necessário ressaltar que esse envolvimento entre pesquisador e o grupo de samba pesquisado ocorreu somente em aspectos que não vieram comprometer o caráter científico da pesquisa, ou seja, procurou-se estabelecer uma relação de confiança, de inclusão no grupo, mas buscando evitar que isso causasse o direcionamento ou a modificação do objeto, embora se saiba que tal relação nunca deixa de motivar certas mudanças, mesmo que seja somente de comportamento, de pequenas alterações da rotina.

Antes de começar a navegar pela pesquisa qualitativa, o pesquisador buscou o preenchimento de sua bagagem com aspectos relacionados ao conhecimento prévio, interesse pela temática e valores pessoais condizentes com a realidade, já que tais aspectos incidem diretamente sobre o delineamento da pesquisa e suas interpretações.

Contudo, fez-se necessário conscientizar-se de que esse conhecimento prévio não deve contribuir para que o pesquisador venha interferir nos dados, emitir um parecer já pré-estabelecido ou produzir um saber, uma visão influenciada por valores generalizados e estigmatizados. Assim, empenhou-se, desde o início, em se preparar para a pesquisa, com o intuito de não se deixar influenciar, não repetir ou ratificar uma situação que se consolida através de estereótipos, isto é, não impregnar as interpretações com conceitos prévios, fixados por uma formação pessoal.

Esse posicionamento do pesquisador ante à pesquisa aqui apresentada foi adotado, portanto, com o intuito de evitar o que Said (2007) aponta em sua obra sobre o Orientalismo, na qual mostra o fato de que o Ocidente criou uma visão 
distorcida do Oriente como o "Outro", trazendo uma tentativa de diferenciação que estivesse de acordo com os interesses da política colonialista ocidental, ou seja, o Oriente como "invenção" do Ocidente. Como forma de exemplo, vale apreender o que Said (2007), já na introdução do seu estudo, ressalta sobre os estereótipos que permaneceram e que nos levam a perceber o Oriente como fonte de mistério, corrupção, sensualidade ou (paradoxalmente) iluminação espiritual.

Pode-se chamar essa preparação e esse processo de estudo como uma tomada de consciência, a fim de que não se cometa o erro da política do desmerecimento do outro, através da formação de conceitos discriminatórios e dicotômicos em relação ao tema. Sendo assim, deve-se estar preparado, obtendo o máximo de conhecimento possível sobre a temática da pesquisa, para que esta possa corresponder, da maneira mais fiel possível, à realidade pesquisada, atendendo aos objetivos propostos, sem a interferência de uma visão já enraizada.

Entende-se que não existe uma total neutralidade na pesquisa científica e é essa consciência que leva o pesquisador a conclusões mais precisas, buscando despir-se de suas visões e estereotipias, posicionando-se de modo mais neutro possível, embora se saiba que tal situação, em plenitude, seja inviável, já que não se consegue desvencilhar-se totalmente de uma formação cultural prévia.

Dessa forma, procurou-se apresentar uma descrição, de modo mais detalhado e rigoroso possível, do contexto em que ocorreu a sua realização, do caminho percorrido e ainda de como se procedeu em sua interpretação, permitindo, como versa Ferreira (2004, p. 27), uma "visão caleidoscópica do fenômeno estudado".

Para seu bom emprego, uma metodologia deve se pautar por sua capacidade de adaptação e proveito das fontes. Por isso, buscou-se fazer uma análise da documentação indireta com o levantamento, o fichamento e o estudo de referencial bibliográfico relacionado à temática: samba de roda, identidade cultural, cultura popular, poesia oral, memória, tradição, performance, cultura e afrodescendência, dentre outras abordagens.

Para o embasamento das discussões apresentadas, pode-se contar, nessa viagem, com a companhia de vários autores e seus pressupostos teóricos. Contudo, serão explicitados apenas aqueles de maior expressividade, visto que a lista completa de autores referenciados encontra-se ao final deste estudo.

Para tratar da temática sobre cultura, identidades, memória e tradição, foi fundamental a companhia de estudiosos como: Achugar (2006), Bauman (2005), 
Bergson (1999), Bhabha (2003), Burke (2006), Candau (2011), García Canclini (2006), Hall (2000, 2003), Hobsbawm e Ranger (2002), Le Goff (2003), Nora (1981), Ortiz (2003) e Ricoeur (2007). .

As considerações a respeito do samba de roda foram tecidas, dentre outras, em companhia teórica de Carneiro (1961), Cascudo (2008), Marcondes (1977), Muniz Júnior (1976), Pinto (1990), Siqueira (2012) e Sodré (2007).

Já as questões relacionadas à afrodescendência estiveram pautadas na teoria do seguintes companheiros de viagem: Bastide (1973), Fanon (2008), Munanga (1996, 2006), Oliveira (2006, 2007), Pinho (2010), Reis (2008), Serrano e Waldman (2010) e outros.

Quando se trouxe à baila a temática da poesia oral, cancioneiros e demais aspectos da tradição popular, desde os elementos históricos até os temáticos, a contribuição teórica partiu de Asensio (1970), Batista (1982), Bradesco-Goudemand (1982), Cascudo (2008), Ferreira (1993, 2003, 2010), Freixedo (2003, 2012), Santos (2005, 2012), Santos (2006, 2009), Lemaire (1987, 1995, 2002), Menéndez Pidal (1953), Nogueira (1999, 2012), Nunes (1978), Roméro $(1888,1897)$ e Vasconcellos (1904).

Contribuíram para as discussões acerca da performance, do corpo, da dança e das representações na poesia oral: Fernandes (2012), Lopes (2012), MerleauPonty (1999) e Zumthor (1993, 1997, 2005, 2007, 2010). Quanto à simbologia e as representações trazidas pelas cantigas, estas foram analisadas, principalmente, a partir de Chevalier e Gheebrant (2009) e de Cascudo (2008). Do Dossiê do samba de roda do Recôncavo baiano (2006), muito se utilizou para o conhecimento de teorias, história e caracterização do samba de roda.

Desenvolveu-se, ainda, uma série de pesquisas documentais e de outras possibilidades que se mostraram pertinentes ao estudo, como o acompanhamento da página que o grupo "É na pisada ê" mantém em uma rede social, outros sites e blogs relacionados à história e à cultura da região de Xique-Xique.

Além disso, foram também utilizados como material de pesquisa: o programa da série Bahia de todos os cantos e o programa Rede Bahia Revista, produzidos pela TV Bahia, afiliada da Rede Globo de Televisão, ainda o programa Globo Rural, também exibido pela mesma rede. No entanto, vale ressaltar que, ao fazer uso de tais programas como material de pesquisa, foram tomados os devidos cuidados, para que se fugisse dos estereótipos em que a maioria dos programas desse tipo se aporta, procurando extrair o peso desses estereótipos antes de to- 
má-los como objetos de análise. Tal material foi apenas utilizado como pesquisa complementar, como mais uma fonte de observação, porque o amparo maior se deu nas observações ao vivo das rodas de samba e nas gravações feitas pelo próprio pesquisador.

Após essas incursões teóricas e documentais, seguiu-se viagem, navegando em direção à pesquisa de campo. O percurso desenvolvido a partir desse momento, constou de uma sucessão de procedimentos, os quais nem todos foram previamente definidos e planejados, pois muito se construiu à medida que a pesquisa ia se realizando. Tal pesquisa desenvolveu-se mediante conversas com as sambadeiras e sambadores e outros membros responsáveis pela coordenação e pelo acompanhamento do grupo de samba, procurando-se utilizar de uma forma livre, de entrevistas não padronizadas e não estruturadas, com o intuito de colher informações sobre a história, as características e constituição do grupo e da própria comunidade que este integra.

O primeiro contato estabelecido com os integrantes do grupo de samba "É na pisada ê" deu-se através de ex-alunos do curso de Letras da Universidade do Estado da Bahia (UNEB), campus de Xique-Xique, responsável pela apresentação e pelo entrosamento do pesquisador. Esse foi um momento de extrema importância, visto que foi criado um vínculo de amizade e de confiança entre pesquisados e pesquisador. A partir daí, foi informado ao grupo o propósito do trabalho de pesquisa, o qual buscava adquirir informações sobre a história do grupo de samba, da sua gente e da sua comunidade. Assim, através de uma conversa amistosa, foi explicada a finalidade, o objeto e a relevância da pesquisa, ressaltando a necessidade de colaboração.

Para esses contatos com os integrantes do grupo, era organizado, sempre, um roteiro prévio com as abordagens, de conhecimento somente do entrevistador/ouvinte/interlocutor, já que o objetivo era registrar as histórias narradas sobre o samba, seu povo, sua comunidade, buscando perceber o lugar social dessa poética oral e as suas formas de transmissão. A maior parte das letras das cantigas foi repassada, já transcrita, por uma das integrantes e coordenadora do grupo, embora as letras pudessem ser acompanhadas e ouvidas durante as apresentações nas rodas de samba.

Houve várias participações do pesquisador nas rodas de samba da comunidade em festas de padroeiros, de santos de devoção e outras comemorações. Foi importante também a sua presença em apresentações que o grupo realizava 
em eventos promovidos pela UNEB, através do campus de Xique-Xique, ou da Secretaria Municipal de Cultura do mesmo município. Nesses momentos, foram efetuados registros das apresentações e rodas de samba, por meio de gravação em áudio, vídeo e fotografias.

Ainda em relação às cantigas trazidas na obra, além das repassadas e escritas por integrantes do grupo, algumas outras foram gravadas e transcritas a partir de apresentações do grupo "É na pisada ê" em suas rodas de samba, em eventos e apresentações culturais nos festejos da cidade, das escolas e outras. As cantigas aparecem dispostas em todo o corpo do texto, quando se fazem necessárias para ilustrar, exemplificar as discussões e análises voltadas à poesia oral ribeirinha. Não há uma ordem específica, e uma cantiga pode aparecer mais de uma vez, desde que seja pertinente e exigida durante as incursões analíticas e as considerações feitas acerca dos temas. É o caso da cantiga da piranha, uma das mais cantadas nas rodas de samba, a qual aparece diversas vezes no texto, em várias abordagens.

Sendo assim, nos momentos em que aparecem juntas, recebem uma numeração sequencial, para que se possa localizá-las quando são referenciadas, tomadas como exemplo. Mas essa numeração não lhes será fiel em todo o texto, pois poderá haver situações em que a mesma cantiga apareça agrupada com outras e em circunstâncias temáticas distintas, passando, neste caso, a receber uma numeração diferente. Isso significa que uma cantiga pode aparecer com uma numeração em uma parte do texto e, em outra, receber uma numeração diferenciada. Tal estruturação foi adotada com o intuito de situar melhor o leitor quando este precisar recorrer às cantigas, uma vez que, quanto mais perto da abordagem discursiva, melhor a compreensão e a assimilação das ideias.

Entre o pesquisador e os participantes do grupo de samba, buscou-se estabelecer uma relação de confiança, cumplicidade e interlocução, a fim de que não houvesse nenhuma influência ou modificação de sua rotina, das suas atividades, nem tolhimentos de qualquer ordem e, na medida do possível, eles tivessem a chance de expressar livremente as suas ideias, a sua memória cultural. Durante todos os momentos em que se esteve presente nos espaços de pesquisa, procurou-se fazer observações e registros, por meio de um "diário de campo", da rotina, das conversas informais, do cenário e dos costumes do lugar, enfim, da vivência dessas sambadeiras e sambadores das margens do Velho Chico. Esse emprego da observação participante permitiu o acesso aos eventos sociais coti- 
dianos, em especial, das rodas de samba e festas do grupo, onde as relações e interações puderam ser flagradas, facilitando ainda mais o contato com a poética oral do samba de roda.

Outro procedimento foi a análise dos vídeos e a transcrição de parte das cantigas das rodas de samba, visto que a outra parte foi obtida, como já dito, de uma coordenadora do grupo. Essa etapa pode ser considerada com uma das mais importantes, pois permitiu relembrar e reviver grandes e inesquecíveis momentos da pesquisa. As transcrições foram feitas pelo pesquisador, na íntegra, buscando considerar as suas regras básicas e promovendo, quando necessário, pequenos ajustes e adaptações, no sentido de garantir o entendimento, o estilo e a legibilidade, procurando evitar repetições desnecessárias e truncamentos que viessem a comprometer a beleza dessas cantigas.

Porém, em todo esse processo, nada foi feito de forma aleatória e despadronizada, mas mediante orientações teóricas, buscando proporcionar um certo respeito aos preceitos da oralidade, proporcionando ao leitor o contato com essa manifestação da poética oral que representa a memória cultural do povo ribeirinho. Para tanto, o pesquisador baseou-se nas orientações trazidas na Revista Estudos Linguísticos e Literários. ${ }^{6}$

Além dessas etapas, este estudo foi enriquecido com uma pesquisa complementar sobre a poesia popular medieval galego-portuguesa, realizada na Universidade de Vigo, Galícia, Espanha, proporcionada ao autor deste estudo, através do Programa de Doutorado Sanduíche (PDSE), de responsabilidade da Coordenação de Aperfeiçoamento de Pessoal de Nível Superior (Capes), vinculada ao Ministério da Educação (MEC).

Tal pesquisa se desenvolveu, principalmente, no âmbito teórico e documental, tendo sido realizada sob a coorientação, no exterior, do professor titular da Faculdade de Filologia e Tradução da Universidade de Vigo, Xosé Bieito Arias Freixedo, doutor em Filologia Hispânica (Galego-Português). Durante o período de quatro meses (março a junho de 2014), além do estudo de textos teóricos, cancioneiros e demais documentos que tratam da poesia popular galego-portuguesa, houve ainda a participação em seminários, conferências, grupos de estudo, dentre outras atividades, as quais foram de fundamental proveito para a aquisi-

6 Revista Estudos Linguísticos e Literários, n. ${ }^{\circ}$ 7, Universidade Federal da Bahia (UFBA), Instituto de Letras, Salvador: out. 1988,146 p. 
ção de conhecimentos sobre o respectivo tema e para a construção de análises e demais considerações sobre a poética oral do grupo de samba "É na pisada ê".

Na sequência, por último, consolidou-se a fase da redação, momento em que se procurou apresentar alguns entendimentos teóricos e analíticos sobre o tema dissertado a respeito da poética oral do samba de roda, as memórias, as identidades e as tradições ribeirinhas, com o intuito de trazer uma demonstração de como se processa a tecedura das identidades culturais dos povos das margens do Velho Chico, a partir de sua poética oral, evidenciado suas características, "linhavando" seus traços, pesponteando uma espécie de retrato identitário.

Antes de finalizar este capítulo introdutório, é preciso informar que esta obra é um resultado de adaptação e ampliação da tese de doutorado do próprio autor, na UFBA, defendida em abril de 2015. Sendo assim, por ser oriunda de um processo de doutoramento, convém apontar que algumas considerações e análises advindas desta pesquisa foram apresentadas, parcialmente, sob a forma de comunicação oral em eventos da área, como congressos, simpósios e seminários entre os anos de 2011 e 2015. Por isso, algumas partes desta obra, mesmo que sob a forma de apreciações e exposições ainda não tão completas e exemplificadas, podem aparecer compondo trechos de artigos publicados em anais destes respectivos eventos, como o XIII Congresso Internacional da Associação Brasileira de Literatura Comparada (Abralic), realizado no período de 8 a 12 de julho de 2013, na Universidade Federal da Paraíba (UFPB); o IX Encontro de Estudos Multidiscplinares em Cultura (Enecult), realizado no período de 11 a 13 de setembro de 2013, na UFBA; e o XXV Congresso Internacional da Associação Brasileira de Professores de Literatura Portuguesa (Abraplip), na Universidade do Estado do Amazonas (UEA), realizado entre os dias 8 e 13 de novembro de 2015.

\section{Pespontos estruturais da obra}

Esta viagem pela poética oral ribeirinha está retratada em cinco capítulos que se estruturam e se constroem a partir das relações estabelecidas entre as teorias e as cantigas do samba de roda com seus elementos formadores da memória coletiva, tradições e identidades da população ribeirinha, acrescidos deste capítulo introdutório e das considerações provisórias, as quais encerram temporariamente a discussão levantada neste estudo. 
Prosseguindo ao delineamento deste texto, no capítulo “"Escrevivendo” uma região e um samba de roda”, aborda-se uma descrição da região de Xique-Xique numa perspectiva histórica e geográfica, com informações sobre o processo de povoamento e alguns aspectos socioculturais e econômicos. Procura-se retratar o cenário paisagístico, os povos ribeirinhos, seus costumes e atividades diárias. Traz-se, ainda, uma incursão pelo viés conceitual, característico e histórico do samba no Brasil, de modo geral e de modo particular, entrecruzando com a história do samba local e do grupo "É na pisada ê".

No capítulo "O samba das margens como documento de memória e lugar de representação das identidades”, apresenta-se uma proposta de discussão da poética oral do samba de roda como um espaço de memória plural, movente, fragmentada, que produzem identidades líquidas e múltiplas. Procura-se apresentar uma visão de memória e tradições como estratégias e reinvenções de um povo e sua cultura na construção de suas identidades. Discute-se sobre a pluralidade cultural na representação das identidades ribeirinhas, enfatizando o lugar de destaque das marcas da cultura afrodescendente na composição desse gênero da cultura popular. Trata-se, ainda, da fé e da devoção do ribeirinho, cuja religiosidade se manifesta nos temas das cantigas de samba, bem como nas apresentações do grupo nas festas de padroeiro e em outras celebrações.

Em "A poética do corpo no samba de roda das margens do Velho Chico", passeia-se pela poética do corpo com suas marcas e expressões identitárias, evidenciando a voz, a dança, a performance e a representação teatral como parte expressiva da poesia ribeirinha. Destaca-se, ainda, a presença do humor, do riso, da graça, da alegria, do lúdico, do corpo e dos gestos, comungando a felicidade através das pisadas, dos rodopios, dos giros e das umbigadas, dentre outras atividades performáticas. Por fim, apresenta-se a dança da Sinhá Furrudunga, uma espécie de coreografia desenvolvida por um grupo de sambadeiras e sambadores.

No capítulo intitulado "O retrato de uma comunidade pespontado nas cantigas do samba de roda”, faz-se uma análise das letras das cantigas, relacionando-as com o cotidiano, a história, os valores e costumes da comunidade poética, ressaltando, em sua maioria, a representação do universo feminino, bem como o papel ocupado pelas mulheres dentro da poesia oral ribeirinha. Também são apresentadas considerações sobre um vasto universo simbólico e representativo que compõe as cantigas. 
Os aspectos concernentes à construção das cantigas são detalhados no capítulo “O aspecto formal das cantigas de samba do grupo 'É na pisada ê’”. Neste capítulo, são tecidas considerações acerca da estrutura e da construção das cantigas, como os tipos de versos, estrofes, rimas e outras análises do corpo poético.

Por fim, em “Tecendo redes poéticas, 'linhavando' identidades ribeirinhas: considerações provisórias”, traz-se uma recapitulação sintética da tecedura das identidades, demonstrando como o samba de roda ribeirinho "linhava", em si, um retrato da cultura dos povos das margens do Velho Chico, por meio de marcas e de elementos característicos que navegam por um universo de pluralidade, de diversidade cultural e religiosa. Ressalta-se a presença de aspectos que compõem a cultura afrodescendente e o seu papel na construção das identidades ribeirinhas. Evidencia-se a importância da poética oral do samba de roda para a manutenção e a reinvenção das tradições, para a continuidade de uma cultura rica e diversa, a qual se fortalece cada vez mais nas margens do Velho Chico. Então, conclui-se provisoriamente o texto, já que, nas redes poéticas, a liquidez não permite que se represem as identidades ribeirinhas. Nestas, a movência, a inestancável fluidez não permite a ancoragem segura de um ponto final. 